\title{
Physical Examination - Still Relevant in Sjögren Syndrome
}

These days every article requires disclosure of conflicts. And I have one for this editorial - I am a "physical examination" kind of doctor. Surely that is true of almost all rheumatologists because, despite the advances in ultrasound and magnetic resonance imaging, demonstration of the presence of inflammatory arthritis is still largely based on physical examination. And the usefulness of the physical examination is not limited to rheumatology. The techniques developed by René Laennec in part for his newly invented stethoscope (whispered pectoriloquy, egophony, and fremitus) along with the technique developed by Leopold Auenbrugger (percussion $)^{1}$ are highly sensitive and specific for identifying lung infiltrates and effusions ${ }^{2}$. A seasoned examiner can diagnose aortic insufficiency more accurately than either M-mode or 2-dimensional echocardiogram ${ }^{3}$. Thus, the physical examination remains alive and well.

Sjögren syndrome (SS) is a common problem, perhaps second only to rheumatoid arthritis among conditions that cause an inflammatory arthritis ${ }^{4}$. It can be considered an autoimmune epithelitis ${ }^{5}$, and predominately affects the exocrine organs. In fact, patients with primary SS can be conveniently divided into those that have disease limited to the exocrine glands such as the salivary and lacrimal and those in whom there are systemic manifestations. Such manifestations include the previously mentioned inflammatory arthritis as well as vasculitis, restrictive and obstructive pulmonary disease, peripheral neuropathy, myositis, interstitial nephritis, glomerulonephritis, central nervous system disease, and lymphoma ${ }^{6}$. Lymphoma in the setting of SS is commonly mucosa-associated lymphoid tissue (MALT) lymphoma, but can also be other non-Hodgkin lymphomas 7,8 . While patients with other inflammatory rheumatic diseases are also at increased risk of lymphoma, the risk is definitely greatest among patients with $\mathrm{SS}^{9}$, although lymphoma remains an uncommon complication (Table 1). Nevertheless, predictive and prognostic measures related to lymphoma risk are needed for SS.

In this issue of The Journal, Zampeli and colleagues provide just such a measure ${ }^{10}$. And it is a physical finding.
Comparing 19 SS patients with MALT lymphoma to 57 SS patients without MALT lymphoma, the authors find that a fissured, atrophic atrophy is more common among those subjects with MALT lymphoma (68\%) than those without MALT lymphoma (30\%). Only fissured tongue, more severe hyposalivation, and lymphadenopathy were independently associated with MALT lymphoma in a multivariate analysis.

There are limitations to this study, however. Perhaps the most obvious relates to character of the finding and the physical examination required. If the truth be known, most rheumatologists cannot do this examination. The tip of the protruded tongue was grasped and held by the examiner. I think the last time I grasped and held a protruded tongue was as a medical student rotating on otolaryngology at Parkland Hospital in Dallas, Texas. The tongue was divided into posterior, middle and anterior portions. Then, atrophy was graded on a semiquantitative scale (0-2) in each area and for both filiform and fungiform papillae. Dividing the tongue into thirds I can do, but distinguishing, much less identifying, atrophy of the different papillae is, I am equally sure, beyond me (and most other rheumatologists). In fact, the examiners in the paper were oral medicine specialists. This difficulty goes straight to the heart of the evaluation, diagnosis, treatment, and longterm care of these patients. All this takes a team, and it is difficult for many rheumatologists, even those in a comprehensive medical center, to assemble such a team, which requires not only interest in SS but also expertise in pathology, ophthalmology, oral medicine, and rheumatology, at a minimum ${ }^{11}$. Thus, many physicians will have trouble incorporating this examination of the tongue into the clinical care of SS.

There are other limitations. Because of effects on tongue architecture, patients with diabetes mellitus, iron deficiency, or megaloblastic anemia were excluded. Patients with SS are mostly older adults in whom type 2 diabetes mellitus is a common illness. In addition, any patient with Candida found on periodic acid-Schiff stain of tongue brushings was excluded. Because of xerostomia, oral yeast is a common finding; thus, many patients will be excluded. Of course, this

See Tongue atrophy in SS and MALT, page 1565

Personal non-commercial use only. The Journal of Rheumatology Copyright (C) 2018. All rights reserved. 
Table 1. Lymphoma risk across rheumatic illnesses based on data from the InterLymph consortium from 12 case-control studies of lymphoma in which data on comorbid conditions were collected.

\begin{tabular}{ll}
\hline Disease & Relative Risk as OR $(95 \% \mathrm{CI})$ \\
\hline SS & \\
$\quad$ Primary & $4.75(1.79-12.6)$ \\
$\quad$ Secondary & $9.57(2.90-31.6)$ \\
RA & $1.06(0.87-1.29)$ \\
Psoriasis & $1.16(0.98-1.38)$ \\
SLE & $2.69(1.68-4.30)$ \\
SSc & $0.69(0.20-2.40)$ \\
\hline
\end{tabular}

Data from Ekström Smedby $\mathrm{K}$, et $a l^{9}$. SS: Sjögren syndrome; RA: rheumatoid arthritis; SLE: systemic lupus erythematosus; SSc: systemic sclerosis.

is another part of the examination that general physicians or rheumatologists will not likely be able to replicate in clinical practice. Finally, this study was of MALT lymphoma only. So the results cannot be generalized to all lymphomas to which patients with SS are at risk. And the physical examination finding from this paper cannot be incorporated into other predictive models of lymphoma in SS because these included all lymphoma $a^{7,8,10,12-18}$. The physical findings previously associated with lymphoma risk have been parotid enlargement and splenomegaly ${ }^{18}$.

Patients with SS are at high risk for lymphoma, and those at high risk need to be monitored carefully. Despite some limitations, the findings of Zampeli, et al ${ }^{10}$ add another tool to identify those patients at high risk of this, the most serious complication. Incorporation of this examination into the care of SS should be done by oral medicine providers, or rheumatologists if they are able.

\section{R. HAL SCOFIELD 1 , MD, Departments of Medicine and Pathology, College of Medicine, \\ University of Oklahoma Health Sciences Center; Arthritis and Clinical Immunology Program, Oklahoma Medical Research Foundation; Medical and Research Services, \\ Oklahoma City Department of Veterans Affairs Medical Center, \\ Oklahoma City, Oklahoma, USA.}

Address correspondence to Dr. H. Scofield, 825 NE 18th St., Oklahoma City, Oklahoma 73104, USA.E-mail: hal-scofield@omrf.ouhsc.edu. Supported in part by US National Institutes of Health grants GM104938, AI1082714, and AR053483, as well as a Department of Veterans Affairs Merit Review grant.

\section{REFERENCES}

1. Bynum $\mathrm{W}$. The history of medicine: a very short introduction. Oxford: Oxford University Press; 2018:48-52.

2. Shellenberger RA, Balakrishnan B, Avula S, Ebel A, Shaik S. Diagnostic value of the physical examination in patients with dyspnea. Cleve Clin J Med 2017;84:943-50.

3. Grayburn PA, Smith MD, Handshoe R, Friedman BJ, DeMaria AN. Detection of aortic insufficiency by standard echocardiography, pulsed Doppler echocardiography, and auscultation. A comparison of accuracies. Ann Intern Med 1986;104:599-605.

4. Helmick CG, Felson DT, Lawrence RC, Gabriel S, Hirsch R, Kwoh $\mathrm{CK}$, et al. Estimates of the prevalence of arthritis and other rheumatic conditions in the United States. Part I. Arthritis Rheum 2008;58:15-25.

5. Tzioufas AG, Kapsogeorgou EK, Moutsopoulos HM. Pathogenesis of Sjogren's syndrome: what we know and what we should learn. J Autoimmun 2012;39:4-8.

6. Routsias JG, Goules JD, Charalampakis G, Tzima S, Papageorgiou A, Voulgarelis M. Malignant lymphoma in primary Sjogren's syndrome: an update on the pathogenesis and treatment. Seminar Arthritis Rheum 2013;43:178-86.

7. Papageorgiou A, Voulgarelis M, Tzioufas AG. Clinical picture, outcome and predictive factors of lymphoma in Sjogren syndrome. Autoimmun Rev 2015;14:641-9.

8. Chiu YH, Chung CH, Lin KT, Lin CS, Chen JH, Chen HC, et al. Predictable biomarkers of developing lymphoma in patients with Sjogren syndrome: a nationwide population-based cohort study. Oncotarget 2017;8:50098-108.

9. Ekström Smedby K, Vajdic CM, Falster M, Engels EA, Martinez-Maza O, Turner J, et al. Autoimmune disorders and risk of non-Hodgkin lymphoma subtypes: a pooled analysis within the InterLymph Consortium. Blood 2008;111:4029-38.

10. Zampeli E, Kalogirou EM, Piperi E, Mavragani CP, Moutsopoulos HM. Tongue atrophy in Sjögren syndrome patients with mucosa-associated lymphoid tissue lymphoma: autoimmune epithelitis beyond the epithelial cells of salivary glands? J Rheumatol 2018;45:1565-71.

11. Rasmussen A, Ice JA, Li H, Grundahl K, Kelly JA, Radfar L, et al. Comparison of the American-European Consensus Group Sjogren's syndrome classification criteria to newly proposed American College of Rheumatology criteria in a large, carefully characterised sicca cohort. Ann Rheum Dis 2014;73:31-8.

12. Giannouli S, Voulgarelis M. Predicting progression to lymphoma in Sjogren's syndrome patients. Expert Rev Clin Immunol 2014;10:501-12.

13. Nishishinya MB, Pereda CA, Munoz-Fernandez S, Pego-Reigosa JM, Rua-Figueroa I, Andreu JL, et al. Identification of lymphoma predictors in patients with primary Sjogren's syndrome: a systematic literature review and meta-analysis. Rheumatol Int 2015;35:17-26.

14. Nocturne G, Virone A, Ng WF, Le Guern V, Hachulla E, Cornec D, et al. Rheumatoid factor and disease activity are independent predictors of lymphoma in primary Sjogren's syndrome. Arthritis Rheumatol 2016;68:977-85.

15. Quartuccio L, Baldini C, Bartoloni E, Priori R, Carubbi F, Corazza $\mathrm{L}$, et al. Anti-SSA/SSB-negative Sjögren's syndrome shows a lower prevalence of lymphoproliferative manifestations, and a lower risk of lymphoma evolution. Autoimmun Rev 2015;14:1019-22.

16. Quartuccio L, Isola M, Baldini C, Priori R, Bartoloni Bocci E, Carubbi F, et al. Biomarkers of lymphoma in Sjögren's syndrome and evaluation of the lymphoma risk in prelymphomatous conditions: results of a multicenter study. J Autoimmun 2014; 51:75-80

17. Tomi AL, Belkhir R, Nocturne G, Desmoulins F, Berge E, Pavy S, et al. Brief report: monoclonal gammopathy and risk of lymphoma and multiple myeloma in patients with primary Sjogren's syndrome. Arthritis Rheumatol 2016;68:1245-50.

18. Baimpa E, Dahabreh IJ, Voulgarelis M, Moutsopoulos HM. Hematologic manifestations and predictors of lymphoma development in primary Sjogren syndrome: clinical and pathophysiologic aspects. Medicine 2009;88:284-93. 